\title{
Distribution of Polychlorinated Biphenyls in Soil Around Three Typical Industrial Sites in Beijing, China
}

\author{
Yong-Fei Zhang $\cdot$ Shan Fu $\cdot$ Yuan Dong $\cdot$ \\ Hai-Feng Nie $\cdot$ Zheng Li $\cdot$ Xin-Chun Liu
}

Received: 9 June 2013 / Accepted: 4 February 2014/Published online: 14 February 2014

(c) Springer Science+Business Media New York 2014

\begin{abstract}
We investigated three locations in Beijing, China, containing different industrial plants that may cause pollution of polychlorinated biphenyls (PCBs). The highest soil concentration of $1,000 \mathrm{pg} \mathrm{g}^{-1}$ (dry wt) was found in the chemical plant. The concentrations of $\Sigma$ PCBs tended to decrease with distance from each of the investigated sites. The principal component analysis demonstrated that there were not substantial differences in PCB homologue patterns among these industrial sites. Tri-CBs and tetra-CBs were the dominant congeners. Based on the data obtained in this investigation, further study of the emission of PCBs from these industrial sites in Beijing is warranted.
\end{abstract}

Keywords China Pollution source $\cdot$ Polychlorinated biphenyls · Soil

The group of compounds known as polychlorinated biphenyls (PCBs) was listed as persistent organic pollutants (POPs) by the Stockholm Convention on POPs on May 22, 2001 (Secretariat of the Stockholm Convention and UNEPs Information Unit for Conventions 2005). Soil is generally regarded as an important reservoir for most POPs including

Y.-F. Zhang · S. Fu ( $₫)$ · Y. Dong $\cdot$ H.-F. Nie $\cdot$ Z. Li

State Key Laboratory of Environmental Chemistry and

Ecotoxicology, Research Center for Eco-Environmental

Sciences, Chinese Academy of Sciences,

Post Office Box 2871, Beijing 100085, People's Republic

of China

e-mail: fu_shan@sina.com

X.-C. Liu ( $₫)$

University of Chinese Academy of Sciences, 19A Yuquanlu,

Beijing 100049, People's Republic of China

e-mail: xcliu@yahoo.cn
PCBs (Wang et al. 2012), and thus is often analyzed to establish PCB status in a given environment.

In this study, we investigated three different industrial areas to establish the contamination status of PCBs in the soils. The industrial sites were a solid waste incineration plant, a chemical plant, and a heat and power plant. Each of these industries may cause PCB pollution. In the process of heating and burning solid waste, including many electrical or plastic products that probably contain PCBs, it is possible that some PCBs could be emitted from the incineration plant (Sakai et al. 2001). In the chemical plant, PCBs could be produced as unintended by-products (Schuhmacher et al. 2004), while the heat and power plant contained a significant number of plant units, such as transformers, which contain possible sources of PCBs (e.g., transformer oil) and pose a contamination risk to the surrounding environment (Rubin 1999). This suggests that these industries should be treated as potential pollution sources of PCBs. However, the contamination status of the soils around these areas has received little attention in previous studies.

The industrial sites investigated in our study are located in the Chaoyang, Tongzhou, and Shijingshan districts in Beijing, China. The sites are all located near residential communities, and therefore have the potential to cause health problems or do real harm to local residents. The main objectives of our study were to establish the contamination status, explore the distribution of PCBs in the soils around these different industrial areas, and identify possible sources of pollution.

\section{Materials and Methods}

We collected 32 soil samples from three industrial areas located in Beijing, which has a population of over ten 


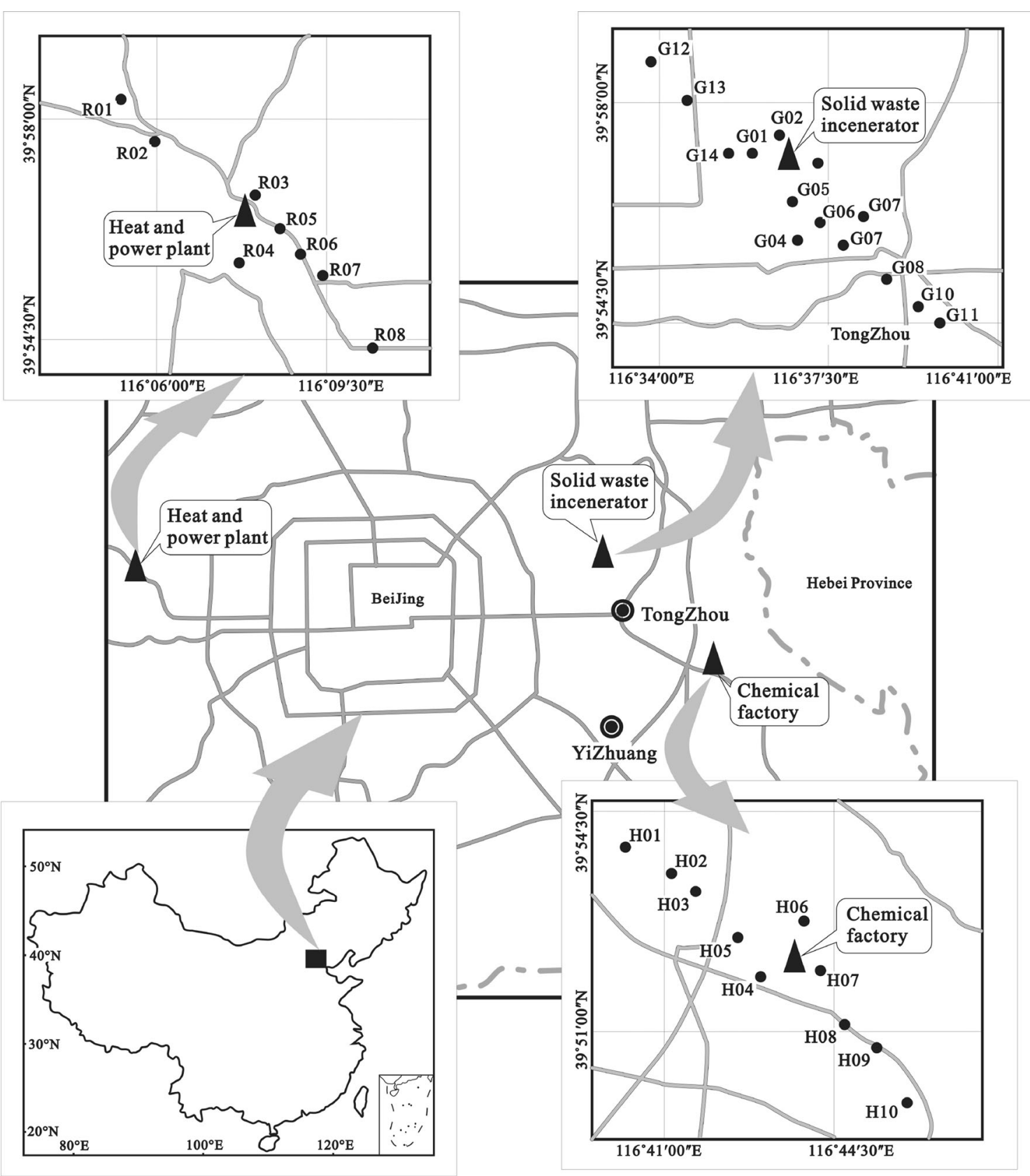

Fig. 1 Sampling sites of three different industry areas in Beijing

million people (Fig. 1). The solid waste incineration plant investigated in this study is the oldest and largest in the city, with more than 3,000 tons of waste delivered to the plant each day. The pollution source sampling site was located close to the incineration building, while the other sampling sites were at distances of 1-5 km away from the plant. The sampling sites were distributed in a line from the northwest to the southeast, in accordance with the main wind direction in the city. The chemical factory commenced operation in 1978, and covers an area of 128 ha. It is the largest acrylic acid plant in China. The heat and power plant is located in the northwestern part of the city, with an installed capacity of $660 \mathrm{MW}$. The sampling locations for these two industrial sites were similar to those for the incineration plant (Fig. 1).

At each sampling point, we collected five surface soil samples $(0-10 \mathrm{~cm}$ in depth) in a square area measuring $100 \times 100 \mathrm{~m}$, and then mixed them together. This sampling method was followed by the technical specification for soil environmental monitoring (HJ/T 166-2004). The samples were then freeze-dried and sifted through a $2 \mathrm{~mm}$ screen. The samples were then stored in brown glass bottles at $-20^{\circ} \mathrm{C}$. 
A standard solution of PCB congeners (Accustandard, CT, USA) was used to quantify 125 congeners. 2,4,5,6Tetrachloro- $m$-xylene (TCMX, as surrogate) was purchased from Supelco (Bellefonte, PA, USA). n-Hexane, dichloromethane, and toluene were pesticide grade (Fisher Scientific, Fair Lawn, NJ, USA). Nonane was GC grade (Fluka, Sigma-Aldrich, Munich, Germany). Anhydrous sodium sulfate, sodium hydroxide, silver nitrate, and sulfuric acid were guaranteed reagent (Sinopharm Chemical, Beijing, China). Silica gel (60-100 mesh) for chromatography was analytical grade (Qingdao Haiyang Chemical, Qingdao, China). Cleanup and analysis of PCBs followed the modified methods of our previous reports ( $\mathrm{Fu}$ et al. 2009)

A laboratory control group was analyzed to demonstrate lack of interference and cross-contamination. A procedural blank in parallel with each set of six samples was also run to further check for interference and cross-contamination. Method repeatability was examined by regular analysis of duplicate samples (Fu et al. 2009).

An external standard method was used to quantify the concentration of PCBs. The measures taken to ensure the integrity of the results are described in our previous report (Fu et al. 2009). Under optimum conditions, the limit of detection (LOD, signal-to-noise ratio $=3$ ) for soil samples was in the range of $0.01-1.7 \mathrm{ng} \mathrm{g}^{-1}$ dry wt for PCBs. The matrix spike recoveries for the 125 PCB congeners (including some co-eluting PCB congeners) ranged from $70 \%$ to $110 \%$, with a standard deviation of $15 \%$. The recovery of TCMX surrogate in all samples was within the range of $70 \%-95 \%$, with an average of $87 \%( \pm 5 \%)$.

Statistical analysis was done using PASW statistics 18.0 (IBM, Armonk, NY, USA). We used principal-component analysis (PCA), a multivariate statistical technique, to derive new principal components (PCs) as a linear combination of the original variables, where $\mathrm{PCs}$ attempt to preserve the statistical relationships of the original data. For this study, we investigated variations in PCB congeners using PCA to deduce the possible sources of PCBs around the three industrial sites.

\section{Results and Discussion}

The concentrations of $125 \mathrm{PCB}$ congeners were determined, and the pollution status around each of the three industrial sites is listed in Table 1. PCBs were detected in all 32 samples, which indicated wide contamination of PCBs in these areas. Around the solid waste incineration plant, the concentration of PCBs ranged from 20 to $950 \mathrm{pg} \mathrm{g}^{-1}$ (dry wt). For the chemical plant and the heat and power plant, the total PCB concentrations ranged from 33 to $1,000 \mathrm{pg} \mathrm{g}^{-1}$, and from 28 to $960 \mathrm{pg} \mathrm{g}^{-1}$,
Table 1 The mean ( \pm error) homologue concentrations in the industrial areas $\left(\mathrm{pg} \mathrm{g}^{-1}\right.$, dry wt)

\begin{tabular}{lccl}
\hline & $\begin{array}{l}\text { Solid waste } \\
\text { incineration } \\
\text { plant }\end{array}$ & $\begin{array}{l}\text { Chemical } \\
\text { plant }\end{array}$ & $\begin{array}{l}\text { Heat and } \\
\text { power plant }\end{array}$ \\
\hline Mono-CBs & $0.25 \pm 0.51$ & $0.18 \pm 0.42$ & 0 \\
Di-CBs & $7.15 \pm 13.1$ & $2.60 \pm 5.00$ & $5.19 \pm 8.58$ \\
Tri-CBs & $62.5 \pm 81.1$ & $12.3 \pm 15.9$ & $32.3 \pm 55.3$ \\
Tetra-CBs & $125 \pm 119$ & $25.9 \pm 14.4$ & $16.9 \pm 24.2$ \\
Penta-CBs & $95.7 \pm 111$ & $129 \pm 251$ & $120 \pm 143$ \\
Hexa-CBs & $47.4 \pm 40.5$ & $22.6 \pm 27.6$ & $70.4 \pm 66.4$ \\
Hepta-CBs & $33.4 \pm 35.1$ & $10.0 \pm 8.58$ & $51.7 \pm 66.7$ \\
Octa-CBs & $22.5 \pm 38.7$ & $3.52 \pm 3.25$ & $2.94 \pm 1.30$ \\
Nona-CBs & $6.62 \pm 10.6$ & $1.04 \pm 1.21$ & $2.04 \pm 3.81$ \\
Deca-CBs & $11.1 \pm 9.43$ & $22.9 \pm 44.1$ & $13.9 \pm 10.5$ \\
$\Sigma$ PCBs & $413 \pm 298$ & $229 \pm 299$ & $314 \pm 298$ \\
\hline
\end{tabular}

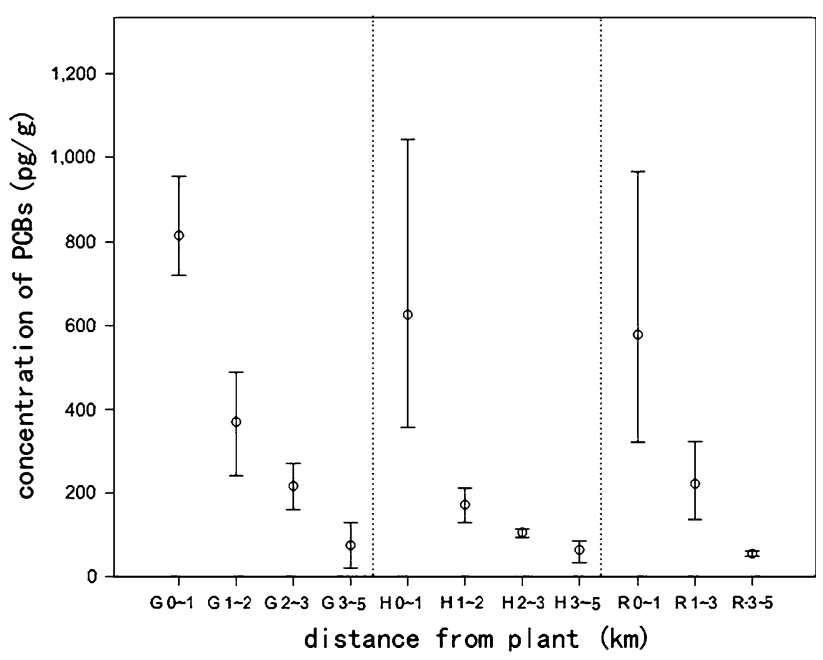

Fig. 2 The total concentrations of PCBs in the investigated sites of varying distances away from each plant (dry mass; G: solid waste incineration plant; $\mathrm{H}$ : chemical factory; R: heat and power plant)

respectively. These PCB levels were compared with soil concentrations of PCBs that have been reported elsewhere. PCB contamination is widespread in China. The levels in our study were similar to those in surface soils in other areas of the country (515 $\mathrm{pg} \mathrm{g}^{-1}$; Ren et al. 2007). Compared with other countries, the levels are similar to those in the surface soils of Asia (580 $\mathrm{pg} \mathrm{g}^{-1}$; Li et al. 2009), and are lower than those in the soils of chemical/petrochemical industrial zones in Spain $\left(657-12,038 \mathrm{pg} \mathrm{g}^{-1}\right.$; Schuhmacher et al. 2004). We consider that the soils in our study generally showed mid-level PCB contamination.

To determine if there is significant difference between the concentrations of total PCBs for the three industrial sites, we performed one-way analysis of variance (ANOVA) among 


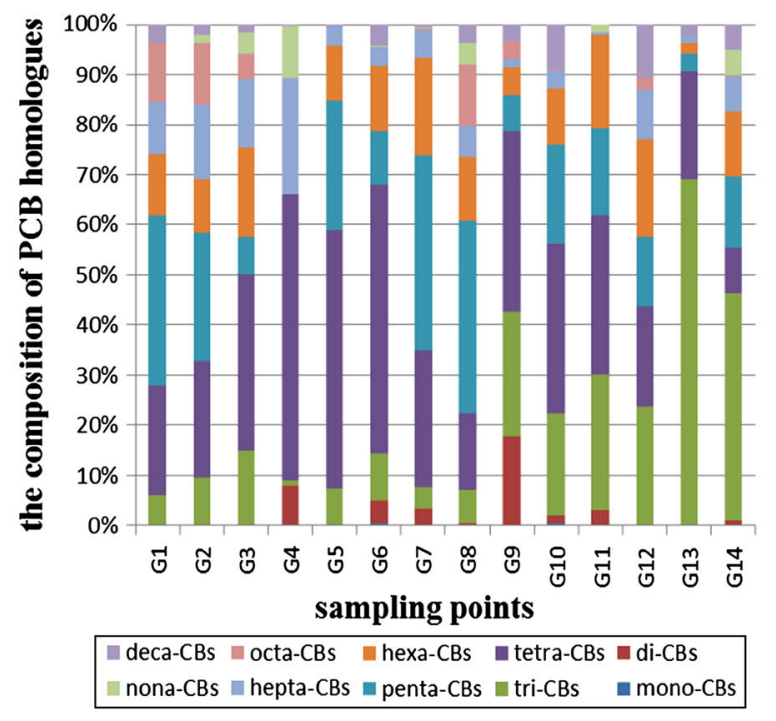

A The solid waste incineration plant

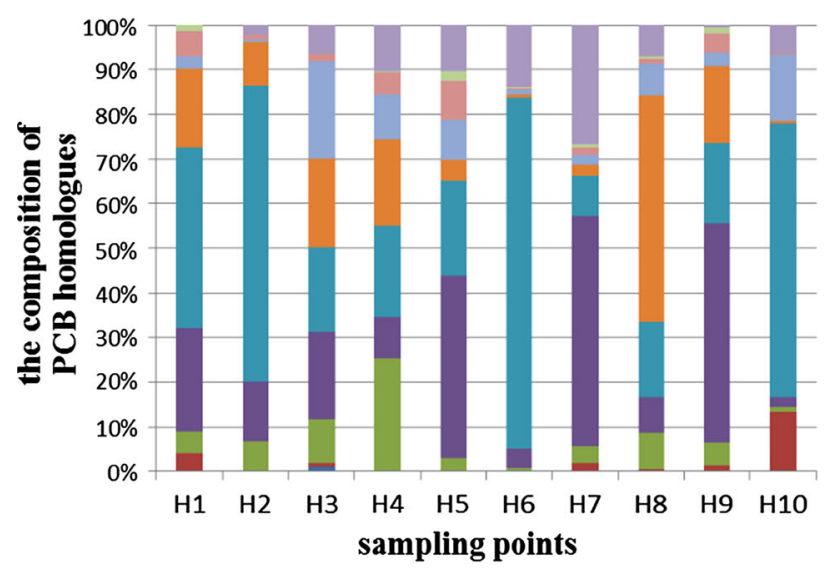

$\square$ deca-CBs $=$ octa-CBs $\square$ hexa-CBs $\square$ tetra-CBs $\square$ di-CBs $\square$ nona-CBs $\approx$ hepta-CBs $\approx$ penta-CBs $\approx$ tri-CBs $\approx$ mono-CBs

B The chemical plant

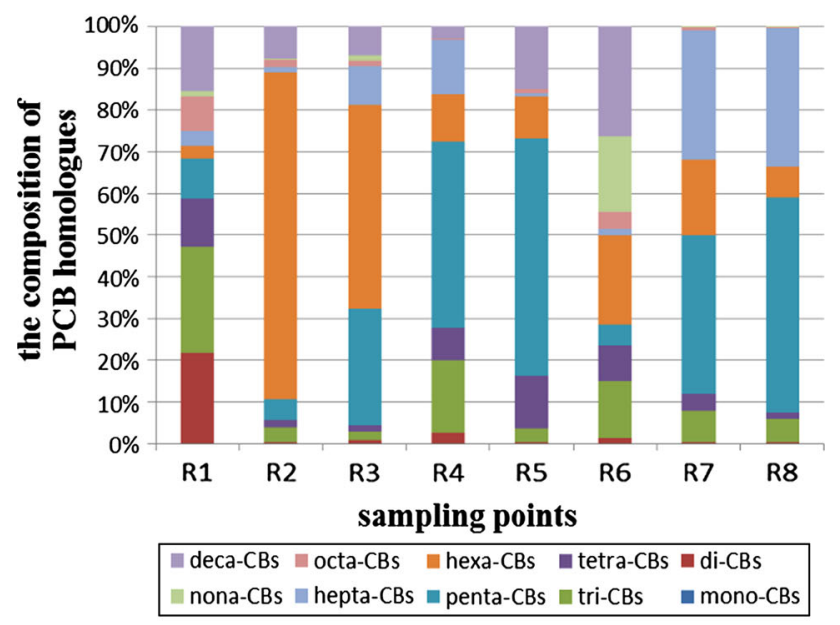

C The heat and power plant
4Fig. 3 Proportion of different PCB homologues in each investigated site from different typical industry areas (G: solid waste incineration plant; $\mathrm{H}$ : chemical factory; R: heat and power plant)

the sites; the $F$ value was 1.12 and the value of significance between groups was 0.34 . We concluded that there was no significant difference between the three sites.

For each of the sites considered in our study, PCB concentrations in the soil samples decreased with increased distance from the plant location. We used the JonckheereTerpstra test to perform a $\mathrm{K}$ independent samples nonparametric test; the asymptotic significance was 0.00 , 0.006 , and 0.012 for the different distances for the waste incineration plant, chemical factory, and heat and power plant, respectively. We concluded that there were significant differences among the distances for the different sites. Figure 2 shows the relationship of the range of PCB concentrations and distance. At each distance, there were about three samples. Figure 2 shows that PCB concentrations at sampling sites close to the plant sites $(<1 \mathrm{~km}$; about $1,000 \mathrm{pg} \mathrm{g}^{-1}$ ) were significantly higher than those at more distant sites; for sites far from the plant (over $5 \mathrm{~km}$ ), the PCB concentrations were less than $100 \mathrm{pg} \mathrm{g}^{-1}$. Thus, it appears that these industrial sites are potential pollution sources of PCBs. It is reported that a PCB pollution source exerts a dominant influence on environmental PCB contamination up to $5 \mathrm{~km}$ away (Bright et al. 1995). In this study, the influence of the industrial sites on PCB concentration also extended to approximately $5 \mathrm{~km}$.

The 125 PCB congeners were divided into ten categories according to the chlorine substitution in the molecule, and these categories were used to characterize the distributions of the different PCB homologs in the three industrial areas (Fig. 3). At the solid waste incineration plant (G series), the major PCB homologs in the soils were tetra-CBs (31\%) and tri-CBs $(19 \%)$. This profile is reasonable because tetra-CBs are the major congeners in municipal solid waste. Sakai et al. (2001) also found that tetra-CBs were the dominant homolog in waste samples from waste incineration. However, tri-CBs have been documented as the main PCB homologs in three kinds of surface soils across China, which is believed to be a reflection of the widespread use of tri-CBs in power capacitors (Ren et al. 2007). At the chemical plant, the major homologs were hexa-CBs (35\%) and tetra-CBs $(22 \%)$. In the research conducted by $\mathrm{Wu}$ et al. (1997), they found that low chloro-substituted PCBs were the dominant congeners in the soils around a chemical factory. In our study, the major congeners around the power plant were also hexa-CBs $(30 \%)$, followed by penta-CBs (24\%). This PCB congener profile is similar to 

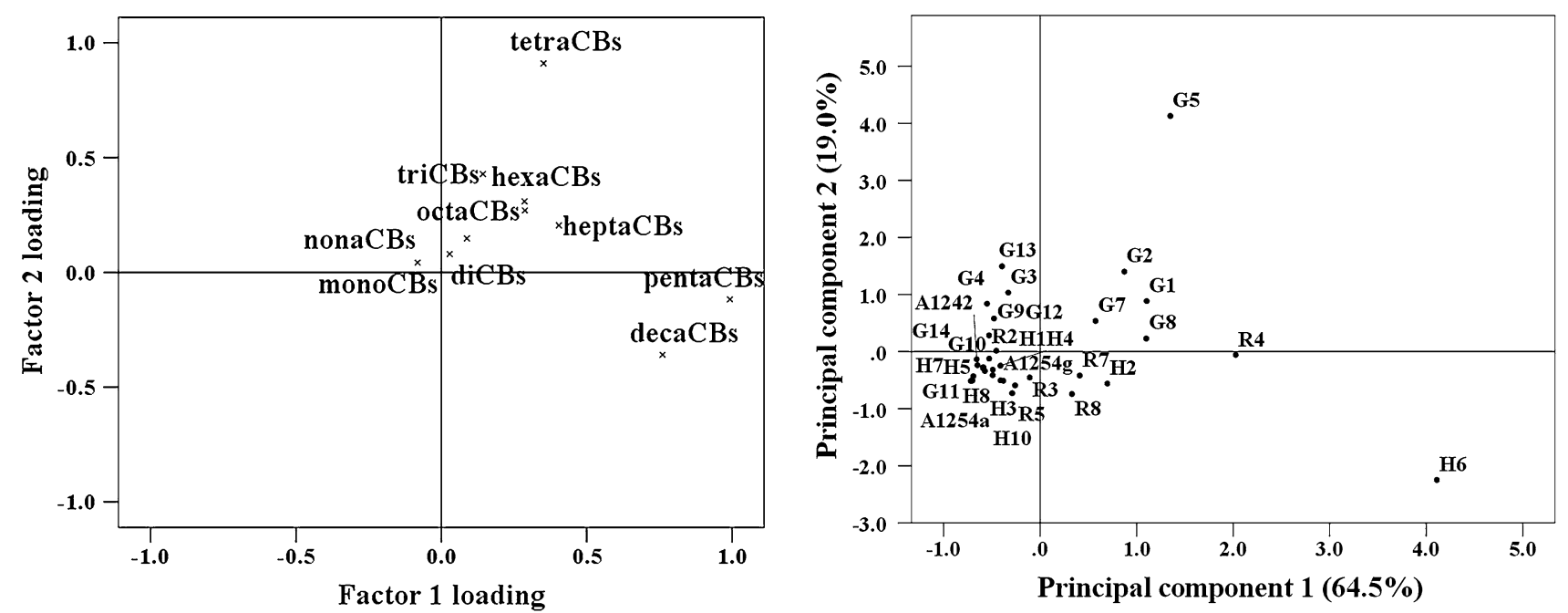

Fig. 4 The PCA loading plot and score plot of PCBs in each investigated site from the different industry areas (G: solid waste incineration plant; $\mathrm{H}$ : chemical factory; R: heat and power plant)

that reported for a fly ash from a power station in India (Sahu et al. 2009). This profile is probably a result of hexaCBs and penta-CBs being formed as unintentional byproducts in the chemical factory and the power plant.

According to the environmental quality standards for soils in China (GB15618-2008), the PCB concentration in soil for the first grade should not exceed $0.015 \mathrm{mg} \mathrm{kg}^{-1}$, and for the second grade, the upper limits are 0.5 and $1.5 \mathrm{mg} \mathrm{kg}^{-1}$ in residential and industrial areas, respectively. The average concentrations around the industrial areas in this study were all below the best grade. To assess the risk posed by PCBs in these areas, toxic equivalent (TEQ) concentrations were calculated using World Health Organization toxic equivalent factors (WHO-TEFs; Van den Berg et al. 1998) based on ten congeners. As for dioxin-like PCBs, the levels of mono-ortho-PCBs were higher than those of the non-ortho-PCBs. In the present study, the concentration of TEQ ranged from undetectable to $0.006 \mathrm{pg} \mathrm{WHO}-\mathrm{TEF} \mathrm{g}^{-1}$. In Sweden, the guideline for the TEQ value in soil is $10 \mathrm{pg} \mathrm{g}^{-1}$ (UNEP 1999), while in Canada the TEQ value should not exceed $4 \mathrm{pg} \mathrm{g}^{-1}$ in soil (Environment Canada 2007). The TEQ concentrations in soil in our study were much lower than the guideline values prescribed in Sweden and Canada.

Aroclor 1242, aroclor 1254a and 1,254 g were commercially produced as PCBs mixtures containing various levels of chlorination. In the current study, the data sets of PCB homologues, aroclor 1242 and aroclor 1254a, 1,254 g were normalized to their percentage compositions and then subjected to PCA using PASW 18.0 to investigate the possible source of PCBs around the three industrial sites. PCAs were extracted for two components with eigenvalues greater than 1, which accounted for $83.5 \%$ of the variability in the original data. Component 1 accounted for
$64.5 \%$ of the total variance and was highly correlated with penta-CBs and deca-CBs, whereas component 2 accounted for $19.0 \%$ of the total variance and was characterized by tetra-CBs. Figure 4 depicts the score plot for the PCB concentration data. The analysis demonstrated that the proportions of each homolog were highly similar among soils collected from either solid waste, chemical, or heat and power plant locations. That each of the soil samples overlapped in the PCA ordination emphasized the similarity of PCB contamination among the soils from the different industrial sites. All samples were characterized by a higher proportion of tri-CBs and tetra-CBs in the $\mathrm{PCB}$ profiles, which indicated that the sources of PCBs for these sampling locations might be associated with the same commercial PCB products. It had been reported that the PCB products produced in China were mainly those featuring lower chlorine substitution (Zhang et al. 2009), and this pattern was also consistent with the major homolog profile of global PCB products (Breivik et al. 2002). Therefore, tri-CBs and tetra-CBs should be the dominant PCBs in soil in Beijing.

Acknowledgments This research was supported by national natural science foundation of China (No. 21177148).

\section{References}

Breivik K, Sweetman A, Pacyna JM, Jones KC (2002) Towards a global historical emission inventory for selected PCB congeners-a mass balance approach: 1. Global production and consumption. Sci Total Environ 290(1-3):181-198

Bright DA, Dushenko WT, Grundy SL, Reimer KJ (1995) Evidence for short-range transport of polychlorinated biphenyls in the Canadian Arctic using congener signatures of PCBs in soils. Sci Total Environ 160-161:251-263 
Chemicals U (1999) Dioxin and furan inventories: national and regional emissions of PCDD/PCDF. UNEP, Geneva, Switzerland

Fu S, Cheng HX, Liu YH, Yang ZZ, Xu XB (2009) Spatial character of polychlorinated biphenyls from soil and respirable particulate matter in Taiyuan, China. Chemosphere 74(11):1477-1484

Li YF, Harner T, Liu L, Zhang Z, Ren N-Q, Jia H, Ma J, Sverko E (2009) Polychlorinated biphenyls in global air and surface soil: distributions, air-soil exchange, and fractionation effect. Environ Sci Technol 44(8):2784-2790

Ren NQ, Que MX, Li YF, Liu Y, Wan XN, Xu DD, Sverko E, Ma J (2007) Polychlorinated biphenyls in Chinese surface soils. Environ Sci Technol 41(11):3871-3876

Rubin ES (1999) Toxic releases from power plants. Environ Sci Technol 33(18):3062-3067

Sahu SK, Bhangare RC, Ajmal PY, Sharma S, Pandit GG, Puranik VD (2009) Characterization and quantification of persistent organic pollutants in fly ash from coal fueled thermal power stations in India. Microchem J 92(1):92-96

Sakai SI, Hayakawa K, Takatsuki H, Kawakami I (2001) Dioxin-like PCBs released from waste incineration and their deposition flux. Environ Sci Technol 35(18):3601-3607
Schuhmacher M, Nadal M, Domingo JL (2004) Levels of PCDD/Fs, $\mathrm{PCBs}$, and PCNs in soils and vegetation in an area with chemical and petrochemical industries. Environ Sci Technol 38(7):1960-1969

Van den Berg M, Birnbaum L, Bosveld A, Brunström B, Cook P, Feeley M, Giesy JP, Hanberg A, Hasegawa R, Kennedy SW (1998) Toxic equivalency factors (TEFs) for PCBs, PCDDs, PCDFs for humans and wildlife. Environ Health Perspect 106(12):775

Wang XP, Sheng JJ, Gong P, Xue YG, Yao TD, Jones KC (2012) Persistent organic pollutants in the Tibetan surface soil: spatial distribution, air-soil exchange and implications for global cycling. Environ Pollut 170:145-151

Wu WZ, Schramm KW, Henkelmann B, Xu Y, Yediler A, Kettrup A (1997) PCDD/Fs, PCBs, HCHs and HCB in sediments and soils of Ya-Er Lake area in China: results on residual levels and correlation to the organic carbon and the particle size. Chemosphere 34(1):191-202

Zhang Z, Qi H, Liu LY, Yang M, Li F (2009) Congener and homologue profiles of polychlorinated biphenyls (PCBs) produced in China. J Nat sci Heilongjiang Univ 26:809-815 